Kansas State University Libraries

New Prairie Press

\title{
THE ANALYSIS OF OVER-DISPERSED COUNT DATA FROM A SINGLE FACTOR STUDY
}

\author{
George A. Capuano \\ Linda J. Young \\ Nancy L. Campbell
}

Follow this and additional works at: https://newprairiepress.org/agstatconference

Part of the Agriculture Commons, and the Applied Statistics Commons

\section{(c) (1) $\Theta \odot$}

This work is licensed under a Creative Commons Attribution-Noncommercial-No Derivative Works 4.0 License.

\section{Recommended Citation}

Capuano, George A.; Young, Linda J.; and Campbell, Nancy L. (1998). "THE ANALYSIS OF OVERDISPERSED COUNT DATA FROM A SINGLE FACTOR STUDY," Conference on Applied Statistics in Agriculture. https://doi.org/10.4148/2475-7772.1278

This is brought to you for free and open access by the Conferences at New Prairie Press. It has been accepted for inclusion in Conference on Applied Statistics in Agriculture by an authorized administrator of New Prairie Press. For more information, please contact cads@k-state.edu. 


\title{
THE ANALYSIS OF OVER-DISPERSED COUNT DATA FROM A SINGLE FACTOR STUDY
}

\author{
George A. Capuano ${ }^{1}$, Linda J. Young ${ }^{1}$, and Nancy L. Campbell ${ }^{2}$ \\ ${ }^{1}$ Biometry Department, University of Nebraska, Lincoln Nebraska 68583-0712, USA \\ ${ }^{2}$ Mathemtics Department, John Carroll University, University Heights, Ohio 44118, USA
}

\begin{abstract}
Methods for analyzing over-dispersed count data in a one-way layout were compared using a Monte Carlo study. Several variance stabilizing transformations were examined as alternatives to analyzing the raw data using a general linear model. Additionally, generalized linear models were fit using a log link. For the generalized linear model, three approaches to account for over-dispersion were investigated: (1) a negative binomial distribution with known $\mathrm{k}$, (2) a Poisson distribution with Pearson's $\chi^{2}$ as an estimate of the scale parameter, and (3) a Poisson distribution with over-dispersion estimated using the deviance. The analysis of the raw data and $\log$ transformed data controlled the size of the tests better than the generalized linear models in the region of the sample space studied.
\end{abstract}

\section{INTRODUCTION}

In agricultural experiments, the response variable is commonly in the form of counts. For example, the effect of a set of treatments on the frequency of a given species of insect or weed may be the focus of a study. Historically, count data have been assumed to come from an underlying Poisson distribution where the mean and the variance are equal. However, in practice, count data are usually characterized by over-dispersion where the sample variance exceeds the mean (McCullagh \& Nelder, 1989). The presence of over-dispersion in count data indicates that the assumption of a Poisson distribution may be questionable and suggests the use of alternative approaches.

The negative binomial distribution is well-documented in the literature as often providing a good fit for over-dispersed count data (Young \& Young, 1998). The following parameterization of the distribution is frequently encountered in biological applications (Anscombe, 1949) :

$$
p(y)=\left(\begin{array}{c}
k+y-1 \\
k-1
\end{array}\right)\left(\frac{k}{\mu+k}\right)^{k}\left(\frac{\mu}{\mu+k}\right)^{y}, \quad y=0,1,2, \ldots
$$

where $\mu$ is the mean and $\mathrm{k}$ is the over-dispersion parameter. The variance function associated with the negative binomial can be written as $V(Y)=\mu+\mu^{2} / k$. As $k$ approaches infinity, the negative binomial converges in distribution to the Poisson. 
Traditionally, the analysis of count data has been based on the analysis of variance using the general linear model:

$$
y=X \beta+\epsilon
$$

where $\mathbf{y}$ is an $\mathrm{n} x 1$ vector of response variables, $X$ is an $n \times p$ design matrix, $\beta$ is a $p \times 1$ vector of unknown parameters and $\epsilon$ represents an $n \times 1$ vector of residuals distributed normally with mean zero and variance $\sigma^{2}$. Clearly, count data are not normally distributed. Further, if the means are unequal, heterogeneity of variances is a concern. In cases where the assumption of homogeneity of variance may have been violated, transformations can be used to stabilize the variance. The analysis of variance can then be performed on the transformed scale. Use of the F-test to test for differences in treatment means has been well established, e.g. Scheffé (1959), Box (1954).

A promising alternative to the standard linear model is the generalized linear model introduced by Nelder and Wedderburn (1972). One of the main advantages of a generalized linear model is that it permits any probability distribution from the exponential class to be incorporated into the model. The generalized linear model is defined in terms of three components:

1. A set of independent response variables $Y_{1}, Y_{2}, \ldots Y_{n}$, each share a distribution from the exponential family whose probability density function can be written in the form:

$$
f(y \mid \theta, \phi)=e^{(\theta a(y)-b(\theta)) / a(\phi)-d(y, \phi)} h(\phi, y)
$$

where $\theta$ and $\phi$ are constants. In the above parameterization, $\theta$ and $\phi$ are referred to as the canonical parameter and the scale (or dispersion) parameter, respectively.

Additionally, it can be shown that $\mathrm{E}(\mathrm{Y})=\mu=\mathrm{b}^{\prime}(\theta)$ and $\mathrm{V}(\mathrm{Y})=\mathrm{a}(\phi) \mathrm{b}^{\prime \prime}(\theta)$.

2. A systematic component that consists of a set of parameters $\beta_{1}, \beta_{2}, \ldots, \beta_{p}$ and explanatory variables $\mathrm{X}_{1}, \mathrm{X}_{2}, \ldots, \mathrm{X}_{\mathrm{n}}$.

3. A montonic, differentiable link function $g(\cdot)$ between the systematic and random components such that $g(\mu)=X^{\prime} \beta$ where $\mu=E(Y)$.

In the generalized linear model, the scale parameter $\phi$ is a measure of goodness-of-fit and can therefore be used to assess the level of over-dispersion present in a model. The scale parameter can also be used as an estimate of the variance. This study examines two methods for estimating the scale parameter $\phi$. The first method equates Pearson's $\chi^{2}$ divided by its degrees 
of freedom to the scale parameter. Pearson's $\chi^{2}$ statistic takes the form

$$
\chi^{2}=\sum(y-\mu)^{2} / V(\mu)
$$

where $\mathrm{V}(\mu)$ is the estimated variance function of the distribution. The second method of estimating the scale parameter equates the deviance divided by its degrees of freedom to the scale parameter. The deviance function takes the form

$$
D=2[l(y ; y)-l(\mu ; y)]
$$

where $1(y ; y)$ and $1(\mu ; y)$ are the maximum likelihood functions associated with the full model and the model under the null hypothesis, respectively. Using a generalized linear model under Poisson distributional assumptions, the scale parameter can be estimated by Pearson's $\chi^{2}$ or the deviance function. Additionally, a generalized linear model based on the negative binomial distribution or some other over-dispersed distribution may be used.

The goal of this Monte Carlo study is to determine the most effective analysis of overdispersed count data when using either general linear models or generalized linear models.

\section{DESIGN OF STUDY}

A Monte Carlo study was performed to evaluate the use of general linear models and generalized linear models for analyzing over-dispersed count data. The study was performed using the $\mathrm{SAS}^{\circledR}$ System. For each combination of parameters, negative binomial count data from a completely randomized experiment were simulated 1000 times. The choice of overall means $(\mu=0.5,1,2,5,10)$, the over-dispersion parameter $(\mathrm{k}=0.5,1,2,5,100)$, and replications $(\mathrm{r}=2$, $4,5,10,50)$ reflect values commonly encountered in experiments from entomology and the weed sciences. The Poisson distribution is well-approximated when $\mathrm{k}=100$.

The study was conducted for two, four and ten treatments. The analyses performed using a linear model include:

1. F-test on the raw data

2. F-test on the data that have been transformed by taking the logarithm of the count plus 1 (by adding one, the transformation is well-defined for a count of 0 )

3. F-test on the square root transformed data

4. F-test on data that have been transformed using the following trigonometric transformation related to the negative binomial distribution:

$$
z=\sqrt{k} \sinh ^{-1}(\sqrt{(y+0.5) / k})
$$


The four generalized linear models that were investigated were based on the following distributions:

1. Poisson

2. Poisson using Pearson's $\chi^{2}$ as an estimate of the scale parameter

3. Poisson using the deviance as an estimate of the scale parameter

4. negative binomial, assuming $\mathrm{k}$ is known

\section{RESULTS}

The estimated and nominal type I error rates for testing the effect of treatment for each analysis at the $0.01,0.05$ and 0.10 levels of significance were compared in order to determine the tests that best controlled size. Some of the simulations results are presented in Table 1.

The general linear model approaches will be considered first. Overall, the analyses of raw and transformed data based on the general linear model performed well across most of the parameter space. However, the analysis associated with the inverse hyperbolic sine transformed data tended to be liberal for small $\mathrm{k}$ and replications fewer than four. For example, at $\mathrm{r}=2$ replications, $\mathrm{k}=0.5$ and $\mu=0.5$ and 1 , the observed type I error rates were 0.11 and 0.08 , respectively, at the 0.05 nominal level. Based on its performance in this region of the parameter space, this analysis will not be considered further. The remaining three approaches based on analysis of raw, log transformed, and square root transformed data performed well in all cases. As the number of replications or the mean decreased, the test based on the raw data tended to be slightly conservative (see Figure 1 for an example) and those of the transformed data tended to be slightly liberal.

The analyses associated with the generalized linear model will be considered next. Except in the approximate Poisson case $(\mathrm{k}=100)$, the $\chi^{2}$ statistic for testing treatment effect for the generalized linear model with the scale parameter set equal to one was inferior to all other analyses considered. For example, for $\mu=5$ and $\mathrm{k}=0.5$, the estimated type I error rates were 0.86 for both 10 and 50 replications when using a 0.05 nominal level. Clearly, accounting for over-dispersion is critical. Therefore, this test will not be considered further.

For the generalized linear models, both $\chi^{2}$ and F-statistics were examined using the deviance and Pearson's $\chi^{2}$ statistic to estimate the scale parameter. First consider the deviance as an estimate of the scale parameter. A comparison of the type I error rates reveals that the estimated level of significance is closer to the nominal level for the F-statistic than for the $\chi^{2}$ statistic. In many cases, the observed type I error rate associated with the $\chi^{2}$ - statistic is twice that of the observed level of the F-statistic (see Figures 2 and 3). The F-test tends to be liberal when over-dispersion is large while it performs more closely to the stated levels of significance as over-dispersion decreases (see Figure 3). However, based on the excessive error rates encountered using the $\chi^{2}$-statistic to test treatment effects, it will no longer be considered as an alternative to the F-statistic when the deviance is used to account for over-dispersion. 
Next, consider the $\chi^{2}$ and F-statistics associated with testing for treatment effects in the generalized linear models, using Pearson's $\chi^{2}$ to estimate the scale parameter. With few exceptions, the observed type I error rates were closer to the stated levels for the F-test than for the $\chi^{2}$-test. As the number of replications decreased, the difference between the two test statistics became more pronounced. For example, at the 0.05 significance level, with $r=4$ replications, $\mathrm{k}$ $=0.5$, and means of 0.5 and 1 , the observed type I error rates were, respectively, 0.15 and 0.12 , using the $\chi^{2}$-statistic as compared to 0.08 and 0.06 , respectively, for the F-statistic. To further illustrate, the estimated type I error rates for a 0.05 nominal level were approximately 10 to $16 \%$ for the $\chi^{2}$-test and between 4.5 and $8 \%$ for the F-test (see Figures 4 and 5). Therefore, the $\chi^{2}$ statistic is no longer considered as an alternative to testing the effect of treatment when compared to the F-test when using Pearson's $\chi^{2}$ to account for over-dispersion.

The final model that was considered was the F-test associated with a generalized linear model using the negative binomial distribution to account for over-dispersion. The level of significance held well across moderate $\mu$ and $\mathrm{k}$ for moderate numbers of replications (see Figure 6). However, this model appeared overly conservative and lack of convergence became an important issue for small means and few replications in the presence of over-dispersion. For example, for $r=2, k=0.5$, and $\mu=0.5$, the observed type I error rates were less than 0.01 , for the 0.05 nominal level. The extremely conservative behavior may be related to the frequent lack of convergence. Convergence rates for this model ranged from approximately 33 to $38 \%$ for two replications and approximately 77 to $83 \%$ for four replications. Based on its poor performance at small $\mu$ and $\mathrm{k}$ as well as the associated convergence problems, this model appears to be suitable only for a limited area of the sample space.

\section{SUMMARY}

This simulation study is the first to compare the performance of the general linear model and the generalized linear model for analyzing over-dispersed count data in a one-way layout. However, this study is far from comprehensive. The results for this study have focused on examining type I error rates as a means for comparing the various analyses. The following recommendations are based on the results of our Monte Carlo study:

1. The F-tests associated with the general linear model analysis of the raw and transformed data performed as well or better than the generalized linear models across the region of the parameter space considered here.

2. Over-dispersion needs to be considered when using generalized linear models. Ignoring over-dispersion results in type I error rates well above the stated level of significance. However, accounting for over-dispersion in an approximately Poisson case does not adversely affect the performance of the generalized linear model analysis.

3. Generalized linear models are not recommended for designs with few replications or when treatment means or $\mathrm{k}$ may be small as the chance of encountering convergence 
problems increases.

4. Overall, the F-test based on Pearson's $\chi^{2}$ estimate of the scale parameter performed better than the $\chi^{2}$-tests or tests using the deviance to estimate over-dispersion. However, it did not perform as well as the general linear model tests based on either raw or transformed counts.

5. Generalized linear models based on the negative binomial with a known $\mathrm{k}$ are a reasonable alternative for designs with moderate treatment means and replications. However, knowledge of $\mathrm{k}$ is required and misspecification of $\mathrm{k}$ may lead to type $\mathrm{I}$ error rates that differ markedly from the stated level of significance. Additionally, when the number of replications is small (less than 5), convergence errors are more likely .

The results of our study are consistent with the findings of previous studies. For example, Barnwal and Paul (1988) studied the performance of two $\mathrm{C}(\alpha)$ statistics, the likelihood ratio statistic, and F-test based on transformed data in a one-way layout of negative binomial count data. Though the $\mathrm{C}(\alpha)$ statistics are recommended, the F-tests based on transformed data hold the level of significance well. Additionally, Lin and Sanford (1983) examined the robustness of the likelihood ratio test, the Kruskal-Wallis sum rank test as well as the general linear model F-tests using the same analyses (except hyperbolic sine) investigated in this study for data from Poisson and negative binomial distributions. The negative binomial distributions included in their study had generally larger means and k's than those in our study. Their findings indicate that the $\mathrm{F}$ - test is robust for small sample sizes with respect to the negative binomial distributions studied. Though the Kruskal-Wallis sum rank test was determined to be acceptable, the F- tests consistently performed better.

It appears that while the generalized linear model does perform well in some cases, use of a general linear model analysis of either raw or transformed data is preferred for analyzing over-dispersed count data in a one-way layout when means are suspected to be small.

With the advancement in methods available in popular statistical packages, it is possible for a researcher to do analyses of cound data with "generalized" linear models methods that are specifically designed for such data. On the surface, this may give the appearance of superiority over old methods that rely on traditional linear models being applied to transformations of the counts. However, inferential procedures for generalized linear models rely primarily on asymptotic theory for their justification. As this paper shows, such reliance may have serious problems when dealing with sample sizes typically found in agricultural research.

\section{REFERENCES:}

Anscombe, F.J. 1949. The statistical analysis of insect counts based on the negative binomial distribution. Biometrics 5: 165-173. 


\section{Applied Statistics in Agriculture}

Barnwal, R.K. and S.R. Paul. 1988. Analysis of one-way layout of count data with negative binomial variation. Biometrika 75: 215-222.

Beall, G. 1942. The transformation from entomological field experiments so that the analysis of variance becomes applicable. Biometrika 32: 243-262.

Box, G.F.P. 1954. Some theorems on quadratic forms applied in the study of analysis of variance problems, II. Effect of inequality of variance and of correlation of errors in the two-way classification. Annals of Mathematical Statistics 25: 481-498.

Cox, D.R. 1983. Some remarks on over-dispersion. Biometrika 70: 269-274.

Lin, L.I. and R.L. Sanford. 1983. The robustness of the likelihood ratio test, the nonparametric sum rank test, and F-ratio test when the populations are from the negative binomial family. Communications in Statistics B-Simulation and Computation 12: 523-539.

McCullagh, P. and Nelder, J.A. 1989. Generalized Linear Models, 2nd ed. London: Chapman and Hall.

Miller, R.G., Jr. 1986. Beyond ANOVA, Basics of Applied Statistics. New York: Wiley.

Nelder, J.A. and R.W.M. Wederburn. 1972. Generalized linear models. Journal of the Royal Statistical Society A 135: 370-384.

Scheffé, H. 1959. The Analysis of Variance. New York: Wiley.

Young, L.J. and J.H. Young. 1998. Statistical Ecology: A Population Perspective. Boston: Kluwer Academic Publishers. 
Table 1: Observed Error Rates (Nominal Rate $=0.05$ )

\begin{tabular}{|c|c|c|c|c|c|c|c|c|c|c|c|}
\hline \multirow[t]{3}{*}{$r$} & \multirow[t]{3}{*}{$\mathrm{k}$} & \multirow[t]{3}{*}{$\mu$} & \multicolumn{4}{|c|}{ General Linear Model } & \multicolumn{5}{|c|}{ Generalized Linear Model } \\
\hline & & & \multirow[t]{2}{*}{ Raw } & \multirow[t]{2}{*}{$\sqrt{ } \mathrm{y}$} & \multirow[t]{2}{*}{$\log$} & \multirow[t]{2}{*}{$\sinh ^{-1}$} & \multicolumn{2}{|c|}{ Pearson's } & \multicolumn{2}{|c|}{ Deviance } & \multirow[t]{2}{*}{ NB } \\
\hline & & & & & & & $\mathrm{F}$ & $\chi^{2}$ & $\mathrm{~F}$ & $\chi^{2}$ & \\
\hline \multirow{6}{*}{2} & \multirow[t]{2}{*}{0.5} & 1 & 0.06 & 0.08 & 0.07 & 0.08 & 0.00 & 0.09 & 0.00 & 0.06 & 0.00 \\
\hline & & 5 & 0.06 & 0.06 & 0.07 & 0.07 & 0.06 & 0.22 & 0.05 & 0.18 & 0.03 \\
\hline & \multirow[t]{2}{*}{2.0} & 1 & 0.06 & 0.06 & 0.06 & 0.06 & 0.03 & 0.14 & 0.02 & 0.10 & 0.01 \\
\hline & & 5 & 0.06 & 0.05 & 0.05 & 0.06 & 0.02 & 0.14 & 0.02 & 0.10 & 0.02 \\
\hline & \multirow[t]{2}{*}{100.0} & 1 & 0.04 & 0.07 & 0.08 & 0.07 & 0.02 & 0.12 & 0.01 & 0.09 & 0.00 \\
\hline & & 5 & 0.05 & 0.05 & 0.05 & 0.05 & 0.04 & 0.20 & 0.04 & 0.20 & 0.06 \\
\hline \multirow{6}{*}{4} & \multirow[t]{2}{*}{0.5} & 1 & 0.04 & 0.06 & 0.06 & 0.06 & 0.06 & 0.12 & 0.05 & 0.10 & 0.03 \\
\hline & & 5 & 0.04 & 0.05 & 0.06 & 0.06 & 0.08 & 0.16 & 0.07 & 0.14 & 0.06 \\
\hline & \multirow[t]{2}{*}{2.0} & 1 & 0.05 & 0.06 & 0.06 & 0.06 & 0.06 & 0.12 & 0.04 & 0.09 & 0.04 \\
\hline & & 5 & 0.05 & 0.04 & 0.05 & 0.05 & 0.06 & 0.12 & 0.04 & 0.07 & 0.06 \\
\hline & \multirow[t]{2}{*}{100.0} & 1 & 0.05 & 0.06 & 0.07 & 0.07 & 0.05 & 0.10 & 0.03 & 0.07 & 0.04 \\
\hline & & 5 & 0.06 & 0.05 & 0.05 & 0.05 & 0.05 & 0.10 & 0.04 & 0.09 & 0.05 \\
\hline \multirow{6}{*}{10} & \multirow[t]{2}{*}{0.5} & 1 & 0.03 & 0.04 & 0.04 & 0.05 & 0.07 & 0.10 & 0.09 & 0.12 & 0.05 \\
\hline & & 5 & 0.04 & 0.04 & 0.04 & 0.04 & 0.08 & 0.09 & 0.09 & 0.12 & 0.06 \\
\hline & \multirow[t]{2}{*}{2.0} & 1 & 0.04 & 0.05 & 0.05 & 0.05 & 0.05 & 0.07 & 0.04 & 0.06 & 0.06 \\
\hline & & 5 & 0.05 & 0.05 & 0.04 & 0.04 & 0.06 & 0.07 & 0.05 & 0.07 & 0.06 \\
\hline & \multirow[t]{2}{*}{100.0} & 1 & 0.04 & 0.06 & 0.06 & 0.05 & 0.05 & 0.06 & 0.03 & 0.04 & 0.06 \\
\hline & & 5 & 0.05 & 0.05 & 0.05 & 0.05 & 0.04 & 0.06 & 0.04 & 0.05 & 0.06 \\
\hline \multirow{6}{*}{50} & \multirow[t]{2}{*}{0.5} & 1 & 0.06 & 0.06 & 0.06 & 0.06 & 0.08 & 0.08 & 0.12 & 0.12 & 0.06 \\
\hline & & 5 & 0.06 & 0.06 & 0.06 & 0.06 & 0.08 & 0.08 & 0.12 & 0.12 & 0.07 \\
\hline & \multirow[t]{2}{*}{2.0} & 1 & 0.06 & 0.06 & 0.06 & 0.06 & 0.06 & 0.07 & 0.06 & 0.06 & 0.06 \\
\hline & & 5 & 0.06 & 0.05 & 0.06 & 0.06 & 0.07 & 0.07 & 0.07 & 0.08 & 0.06 \\
\hline & \multirow[t]{2}{*}{100.0} & 1 & 0.06 & 0.06 & 0.06 & 0.06 & 0.06 & 0.07 & 0.04 & 0.04 & 0.06 \\
\hline & & 5 & 0.06 & 0.06 & 0.06 & 0.06 & 0.06 & 0.07 & 0.05 & 0.05 & 0.06 \\
\hline
\end{tabular}




\section{Applied Statistics in Agriculture}

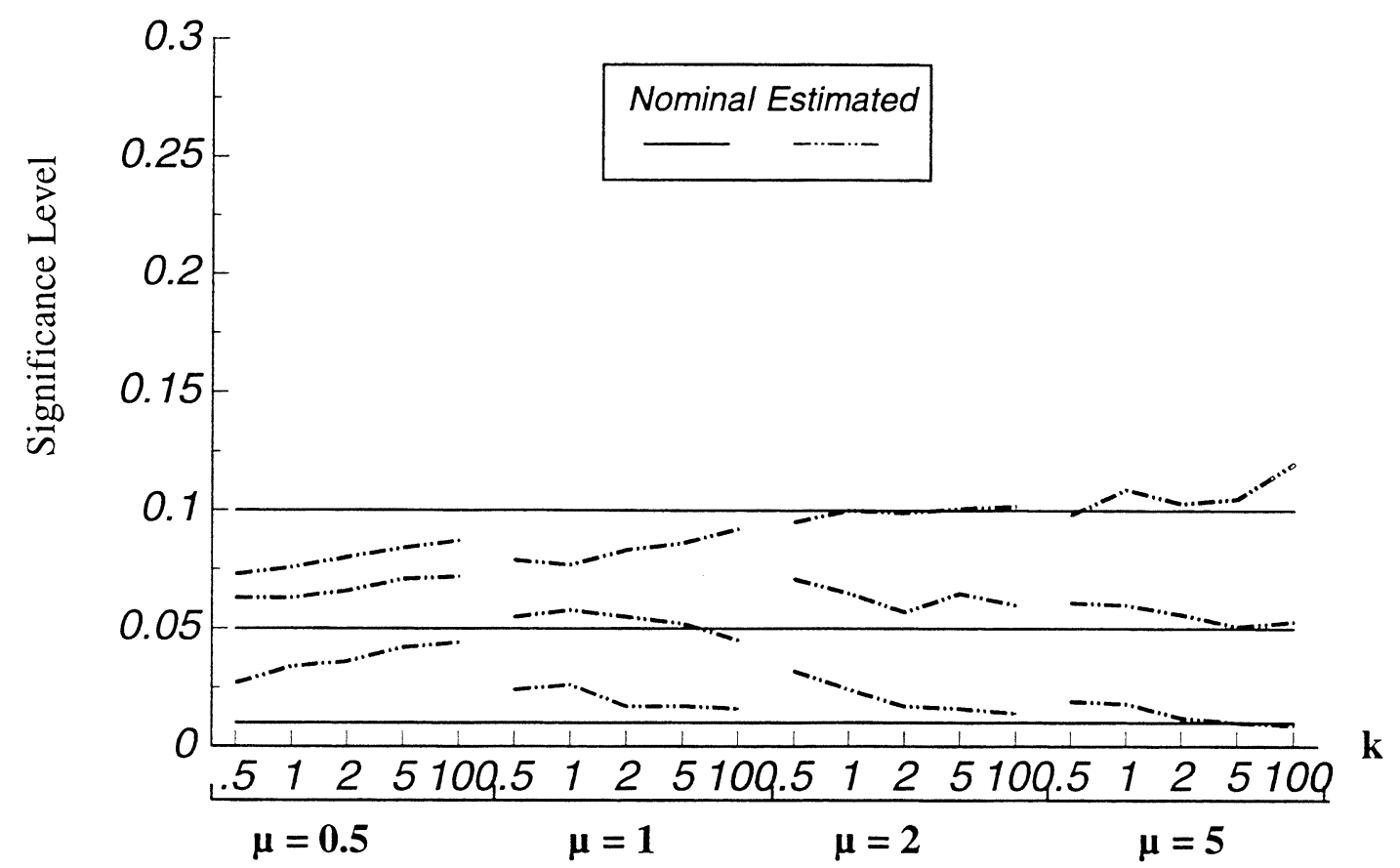

Figure 1. The $0.01,0.05$, and 0.10 estimated (---) and nominal (-) type I error rates for two replications applying the general linear model to the raw data.

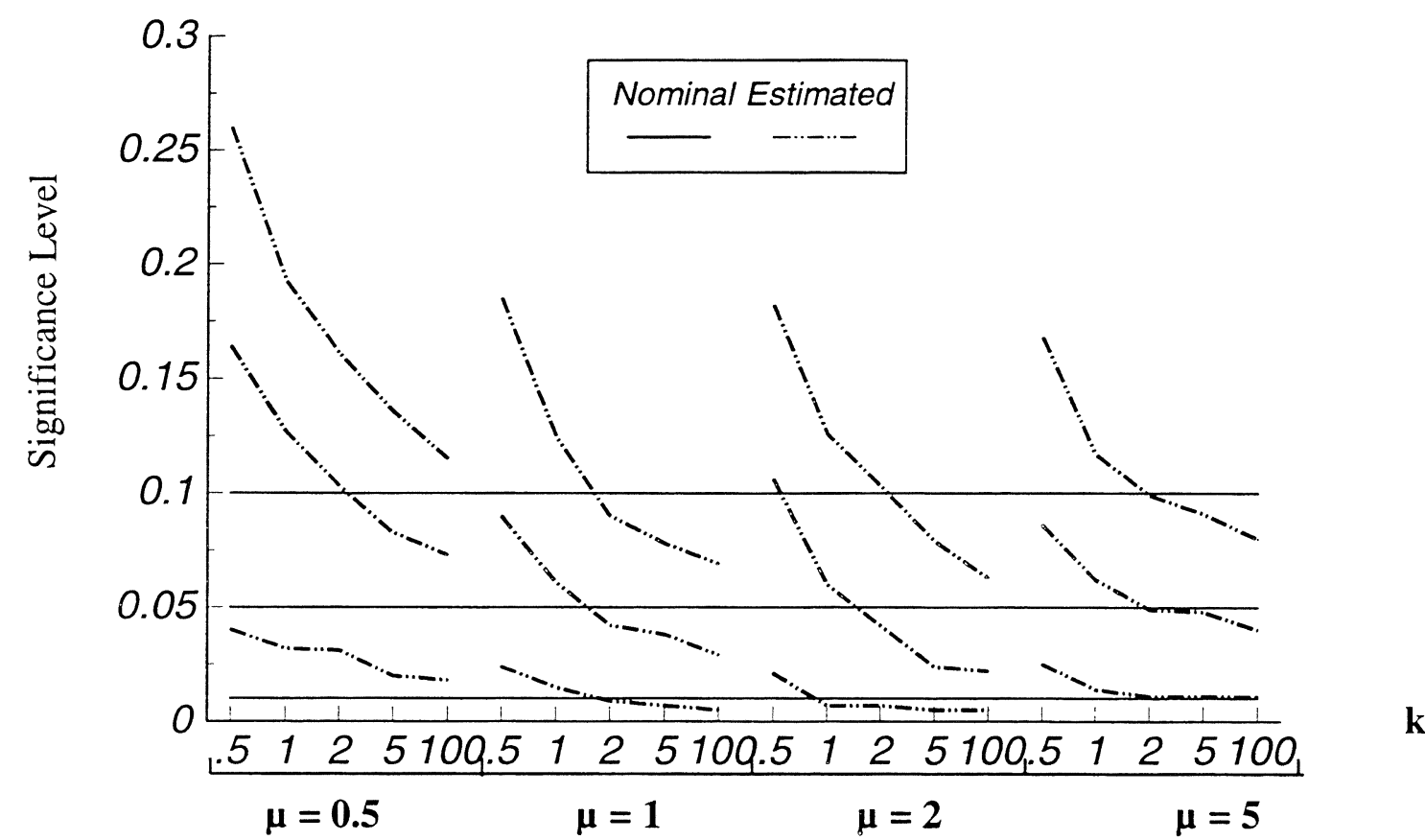

Figure 2. The $0.01,0.05$, and 0.10 estimated (---) and nominal (-) type I error rates for ten replications applying the generalized linear model using the deviance to estimate over-dispersion and the $\chi^{2}$-test. 


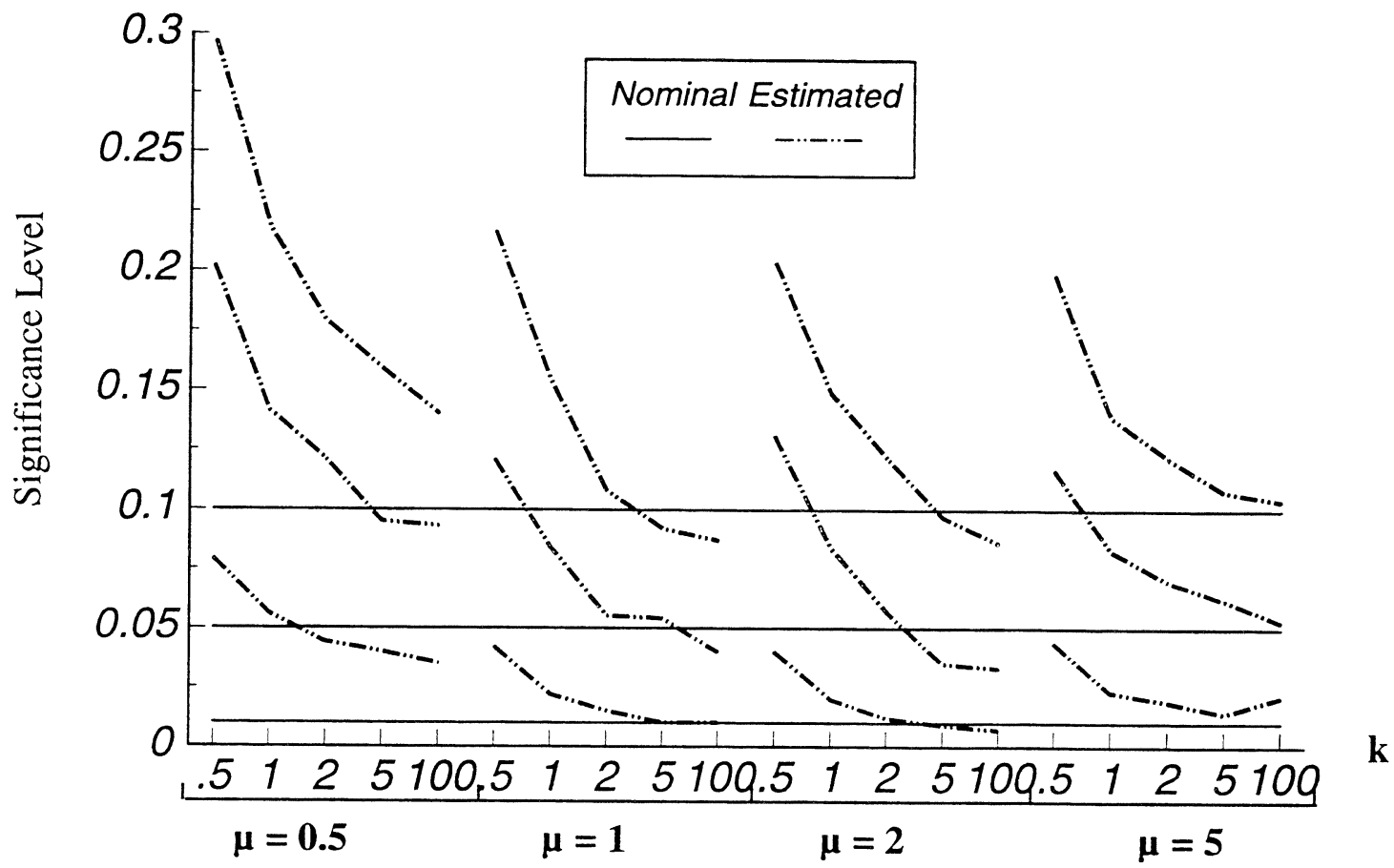

Figure 3. The $0.01,0.05$, and 0.10 estimated (---) and nominal (-) type I error rates for ten replications applying the generalized linear model using the deviance to estimate over-dispersion and the F-test.

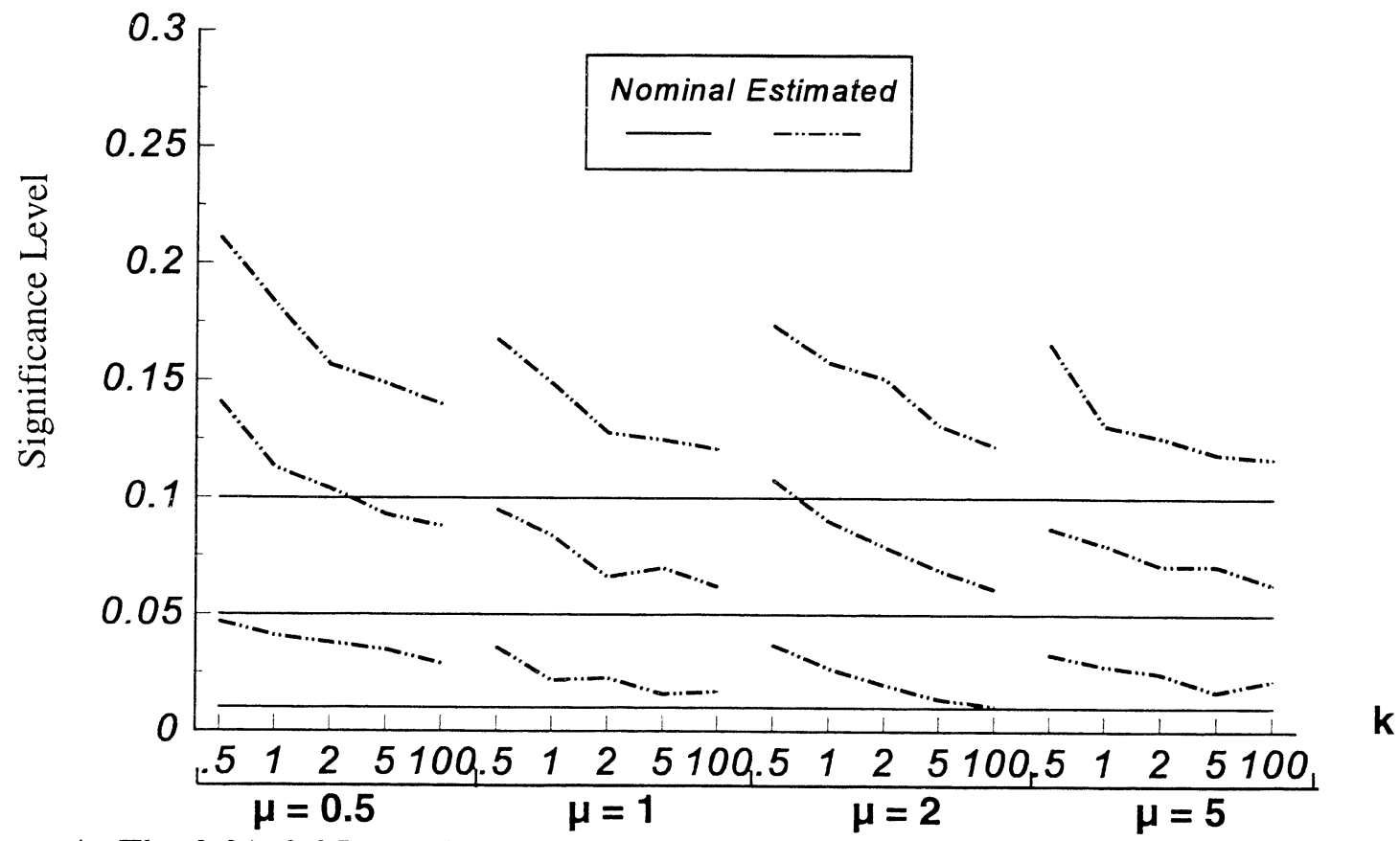

Figure 4. The $0.01,0.05$, and 0.10 estimated (--) and nominal (-) type I error rates for ten replications applying the generalized linear model using Pearson's $\chi^{2}$ to estimate over-dispersion and the $\chi^{2}$-test. 


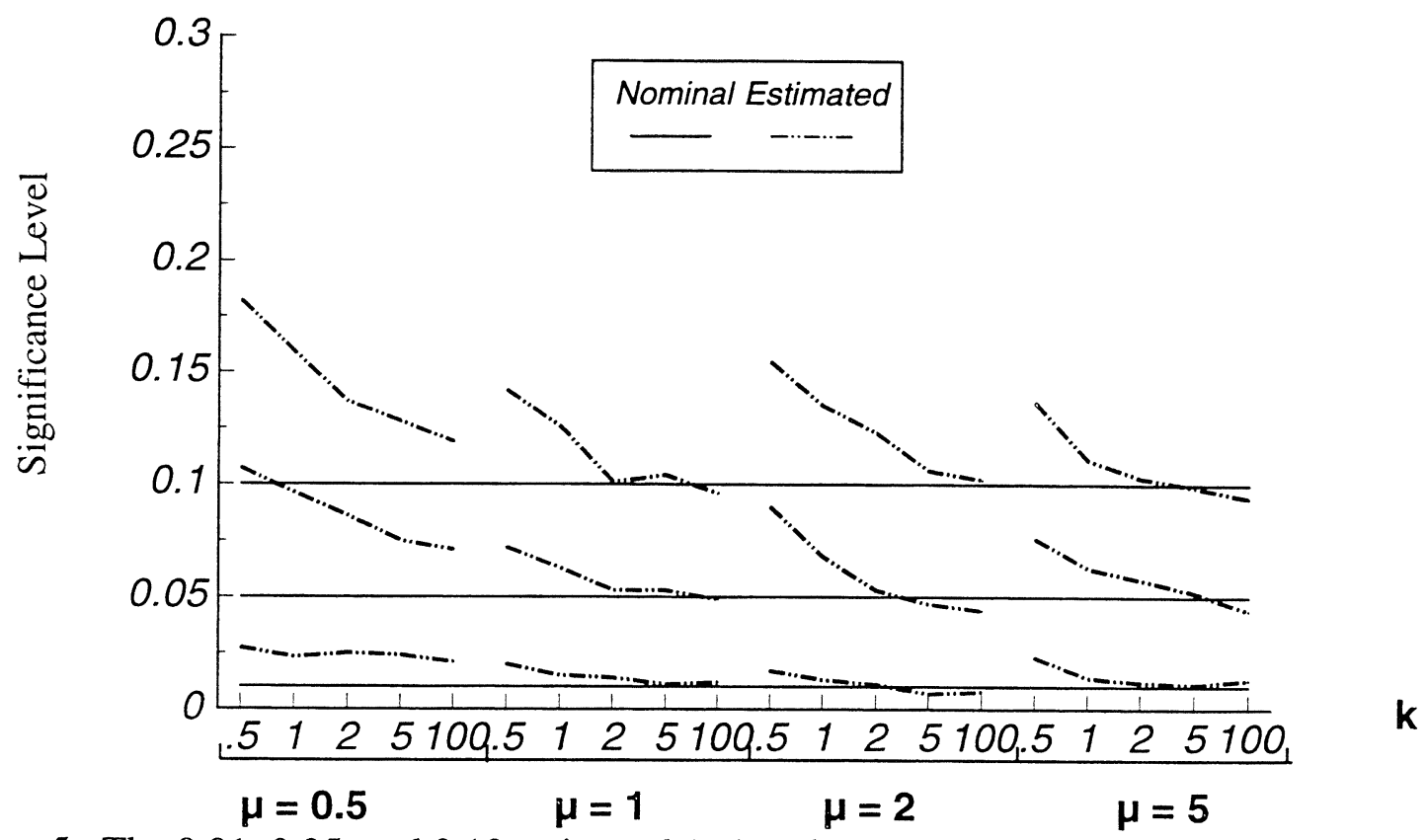

Figure 5. The $0.01,0.05$, and 0.10 estimated (--) and nominal (-) type I error rates for ten replications applying the generalized linear model using Pearson's $\chi^{2}$-test to estimate overdispersion and the F-test..

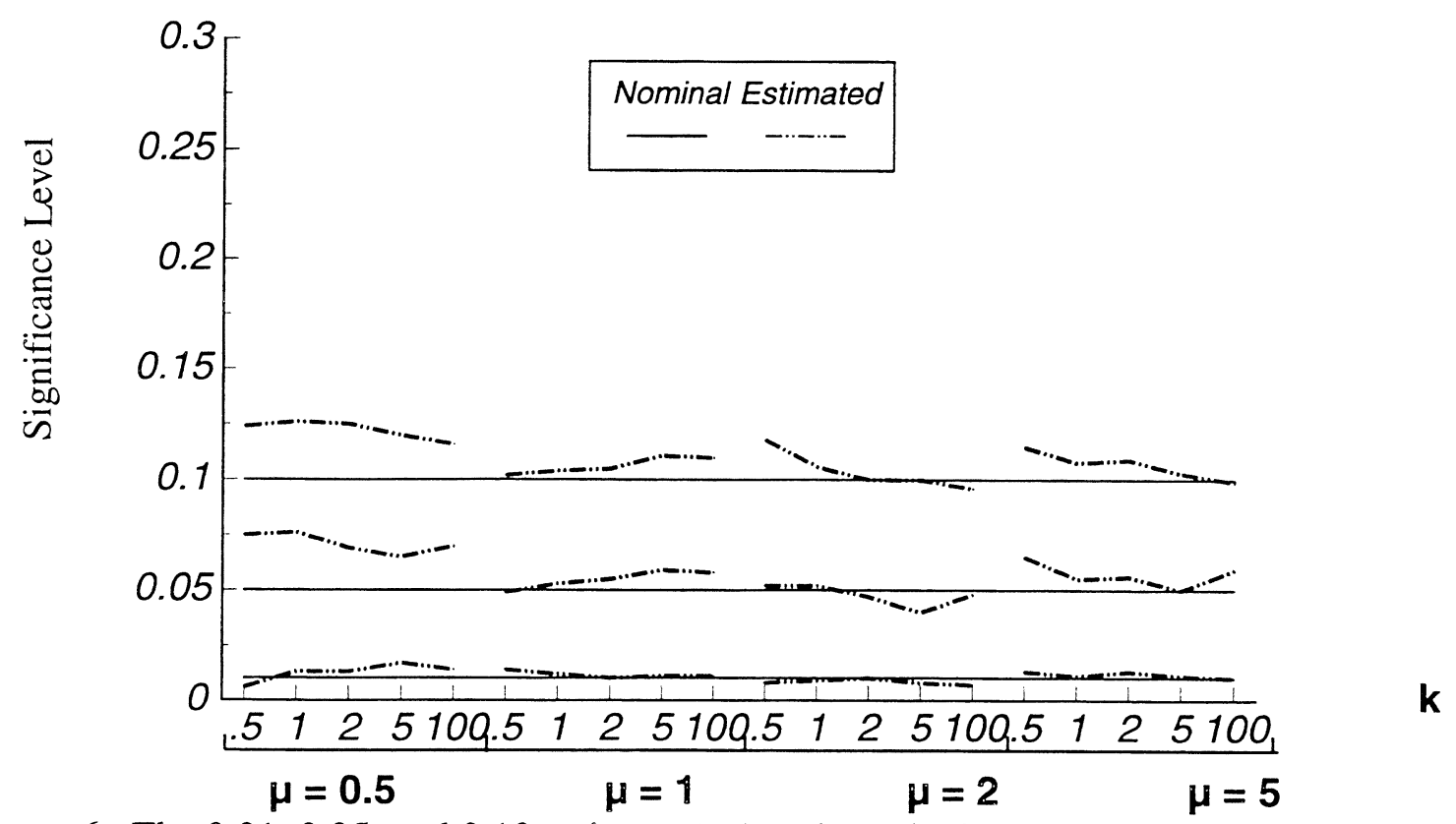

Figure 6. The $0.01,0.05$, and 0.10 estimate (---) and nominal (_) type I error rates for ten replications applying the generalized linear model using the negative binomial with known $\mathrm{k}$. 